J. W. G. van de Kuilen · H. J. Blass

\title{
Mechanical properties of azobé (Lophira alata)
}

Published online: 23 December 2004

(C) Springer-Verlag 2004

\begin{abstract}
The use of tropical hardwoods in structural applications requires knowledge of the mechanical properties. Even though long experience is available with the species azobé (Lophira alata), much of the current knowledge is based on tests performed on small clear specimens for bending, compression and shear. Since tropical hardwoods are used in structures with high economic value, a sound knowledge of the mechanical properties allows for better optimisation and for minimal use of raw material. Bending, compression and shear tests have been performed on material in structural sizes. Characteristic values show that in most loading cases the structural capacity of the material is distinctly higher than currently assumed in practice. The relationship between static modulus of elasticity and bending strength has been determined. The depth effect was shown to be less pronounced than for softwoods.
\end{abstract}

\section{Festigkeitskennwerte von Bongossi (Lophira alata)}

Zusammenfassung Der Einsatz von Konstruktionsholz aus tropischen Hölzern setzt die Kenntnis der mechanischen Eigenschaften dieser Hölzer voraus. Obwohl Bongossi seit vielen Jahren als Bauholz vor allem in bewitterten Konstruktionen verwendet wird, wurden mechanische Kennwerte für Biege-, Druck- und Scherbeanspruchung vor allem aus der Prüfung kleiner fehlerfreier Prüfkörper abgeleitet. Da tropische Hölzer überwiegend in ökonomisch bedeutenden Konstruktionen eingesetzt werden, erlaubt eine bessere Kenntnis der mechanischen Eigenschaften optimierte Konstruktionen sowie Einsparungen insbesondere beim Rohstoff. In

\footnotetext{
J. W. G. van de Kuilen $(\bowtie)$

Faculty of Civil Engineering and Geosciences,

Delft University of Technology, 5048,

2628 CN Delft, The Netherlands

E-mail: J.vandeKuilen@citg.tudelft.nl

H. J. Blass

Lehrstuhl für Ingenieurholzbau und Baukonstruktionen, Universität Karlsruhe (TH), 76128 Karlsruhe, Germany
}

dieser Arbeit wurden Biege-, Druck- und Scherversuche mit Prüfkörpern in Bauholzabmessungen ausgewertet und die entsprechenden charakteristischen Steifigkeitsund Festigkeitskennwerte bestimmt. Die Ergebnisse zeigen, dass Bongossi bessere mechanische Eigenschaften aufweist als bisher angenommen. Die Beziehung zwischen statischem Elastizitätsmodul und Biegefestigkeit wurde bestimmt. Der Höheneinfluss von Bongossi zeigte sich weniger ausgeprägt als für Nadelholz.

\section{Introduction}

Tropical hardwoods are used in structures where both sound mechanical performance and good natural durability are required. Hardwoods are used in bridges, sheet pile walls, sluice doors, heavy piles and harbour works. One of the most important hardwoods used in the Netherlands for these applications is the species azobé (Lophira alata), also known as ekki. This species is widely used not only in the Netherlands, but also in Belgium, the UK, and Germany. Nowadays, structures made with azobé are also exported from the Netherlands to other countries such as the USA and Japan. Undoubtedly, an accurate knowledge of the mechanical properties of the species is of key importance for economic designs. The species was introduced in the Netherlands just after the Second World War, when the Dutch Ministry of Road and Waterworks needed a durable and reliable alternative for many sluice doors, which were traditionally made from oak, treated with creosote or a similar organic compound. The alternative was found in azobé. Azobé has a dark red/brown colour, interlock grain and is found in the tropics of West Africa. The durability of azobe is well known, and the material has proven its performance in many structures that were built during the last decades (Wood Handbook 1999). With the introduction of new design codes, such as the Eurocode 5 (2002), that are based on characteristic values, the need for a thorough investigation of the mechanical properties of this species arose. Many of 
the design rules in the new design codes have been verified for softwoods, but hardwoods have a different structure and may show different strength behaviour. Azobé is assigned to strength class D60 of EN 338 (EN 1912: 1998). One of such behaviours is the volume effect (Weibull 1939). The failure mechanism of softwoods is governed by the amount and location of growth defects such as knots. Knots are virtually non-existent in a tropical hardwood such as azobé, and the failure mode is generally based on grain deviation. Many studies have been carried out regarding the volume effect in timber, but almost all of them focussed on softwoods (Barrett and Griffin 1989; Barrett and Fewell 1990). Currently, the volume effect for bending and tension is dealt with in European standard EN 384 and Eurocode 5 (2002) according to the following equation and based on a reference depth of $150 \mathrm{~mm}$ :

$k_{h}=\left(\frac{150}{h}\right)^{0.2}$

The equation is mainly determined on the basis of test results of softwoods. Bohannan (1966) found an exponent of 0.11 for clear wood bending strength, based on a reference depth of $200 \mathrm{~mm}$, while Fewell and Curry (1983) found 0.4 on the basis of Canadian and British structural softwoods, also for a reference depth of $200 \mathrm{~mm}$. The coefficient of variation in hardwoods is generally between 15 and $20 \%$, whereas in softwoods a coefficient of variation above $20 \%$ is common, even if the material is machine strength graded (Frühwald and Thelandersson 2001). In addition to the new design codes, new strength-grading methods have become available, such as grading using stress waves or ultrasound. However, the applicability of these methods is limited to softwoods (mainly spruce and pine); grading of tropical hardwoods is performed to a much lesser extent. Therefore, the analysis also included the relation between modulus of elasticity (static or dynamic) and bending strength in order to establish an appropriate method to grade tropical hardwoods and azobé in particular. Besides bending strength and stiffness, compression strength and shear strength are also analysed regarding their relevance in the design of columns (compression) and short-span bridge decks (shear).

\section{Materials and method}

Over a period of more than 40 years, tests have been performed with azobé. Generally, the material was obtained from sawmills, but in some cases material from building sites was also obtained where the material had been in service for a number of years. In the following following section, the origin of the data and the tests and measurements performed are given. Material that was directly obtained from the sawmills is indicated with $\mathrm{N}$ (New) and material from building sites is indicated with
O (old). In total, seven new and three old samples are analysed. All data are also analysed as being part of one population. Furthermore, one sample for compression (C) and one sample for shear (S) are analysed.

\subsection{Bending tests}

\subsubsection{Sample N1}

The timber dimensions of the specimens were $50 \times 150$ and 3,300 $\mathrm{mm}$ in length. The beams were tested edgewise in four-point bending with a span of 3,000 $\mathrm{mm}$ with the loads at $1 / 3$ of the span. Span to depth ratio was 20 . In total, 46 beams were tested, all having moisture contents above the fibre saturation point. The moisture content varied between 35 and $52 \%$. The density was based on green volume and oven-dry mass. The density of azobé determined, according to this method can be adjusted to $12 \%$ moisture content by adding $200 \mathrm{~kg} / \mathrm{m}^{3}$ according to (Houtinstituut 1961).

\subsubsection{Sample N2}

The second sample consisted of 40 sheet pile boards with a depth of $30 \mathrm{~mm}$. All boards were tested in four-point bending and in wet condition. The test span was $750 \mathrm{~mm}$ and consequently the span to depth ratio was of 25 . The width of the boards varied between 150 and $276 \mathrm{~mm}$. The static modulus of elasticity and the bending strength were determined (Houtinstituut 1977).

\subsubsection{Sample N3}

This sample consisted of 40 sheet pile boards with a depth of $60 \mathrm{~mm}$ and in this case, the span was $1,500 \mathrm{~mm}$, giving the same span to depth ratio as that of sample 2. The widths of these boards varied between 179 and $315 \mathrm{~mm}$ and the moisture content was between 25 and $43 \%$. In this case, the oven-dry density was also determined, besides the static modulus of elasticity and the bending strength (Houtinstituut 1977). The oven-dry density was adjusted to $12 \%$ moisture content similarly to Sample N1.

\subsubsection{Sample N4}

Thirty-nine sheet pile wall boards with a depth of $60 \mathrm{~mm}$, a width of $300 \mathrm{~mm}$ and a length of $5,700 \mathrm{~mm}$ were tested flatwise in four-point bending to determine the relationship between wet density, mass, dynamic modulus of elasticity and static modulus of elasticity with the strength. Another 50 boards were also tested for static and dynamic modulus of elasticity, but not for strength, since these had to be used for full-scale testing of sheet pile walls. The boards were obtained from five different suppliers in the Netherlands. The test span was $5,400 \mathrm{~mm}$ with the loads at $1 / 3$ of the span. Due to the 
high span to depth ratio of 90 , a special test set-up was built to allow for very large deflections and rotations at the supports and the loading points. All the boards had a trapezoidal tongue and groove profile. There were no indications that this influenced the strength determined in any way (Van der Linden et al. 1996). The moisture content of the boards varied between 17 and 50\%.

\subsubsection{Sample N5}

Sixteen beams with a depth of $150 \mathrm{~mm}$ and a width of $75 \mathrm{~mm}$ were tested in four-point bending. The beams were delivered directly from two sawmills and all had moisture contents above the fibre saturation point. Dynamic modulus of elasticity was determined based on determination of eigenfrequency using a Grindo-sonic machine and with TNO-Wave equipment.

\subsubsection{Sample N6}

This sample contained 25 beams with a depth of $200 \mathrm{~mm}$ and a width of $75 \mathrm{~mm}$. This sample is comparable to sample N5 and was meant to study a possible depth effect. Three sawmills delivered the material, all of which was tested in wet condition. Of these 25 beams five beams, five beams were rejected due to too large grain deviations. Beams with a grain deviation of more than 1:10 are not allowed according to the visual grading rules for azobé in the Netherlands (NEN 5480).

\subsubsection{Sample O1}

From the harbour of Rotterdam, old mooring posts were obtained. From the original sizes of $120 \times 120 \mathrm{~mm}$, 20 boards were manufactured with a depth of $55 \mathrm{~mm}$ and a width of $118 \mathrm{~mm}$. Five of these boards showed large defects and were excluded. The boards were tested in wet condition in four-point bending with $1,500 \mathrm{~mm}$ span, resulting in a span to depth ratio of 27.

\subsubsection{Sample O2}

This sample consisted of 20 boards from a sheet pile wall located in Alphen a/d Rijn. The depth of the boards varied between 50 and $60 \mathrm{~mm}$, while the width varied between 135 and $260 \mathrm{~mm}$. All boards were tested in saturated condition. The boards were sawn from sheet piles that had been in service for 15 years.

\subsubsection{Sample $\mathrm{O3}$}

This sample consisted of 22 boards from a sheet pile wall located in Koudekerk a/d Rijn. The depth of the boards was $50 \mathrm{~mm}$ in all cases, while the width varied between 153 and $283 \mathrm{~mm}$. The span in the test set-up was again $1,500 \mathrm{~mm}$ and consequently the span to depth ratio was 30 in this case. The boards were sawn from fully saturated sheet piles that had been in service for 18 years.

\subsubsection{Sample P1}

The population sample P1 comprises the data available from all the bending samples. The mechanical properties, mainly bending strength and modulus of elasticity, are analysed statistically. The total number of specimens for bending strength and modulus of elasticity is 258 , while for the density and the dynamic modulus of elasticity only the data from samples N4, N5 and N6 are used.

\subsection{Compression tests}

Compression tests (Sample C1) were performed using specimens taken from sample N1. Specimens were manufactured with a cross section of $50 \times 150 \mathrm{~mm}$ and a length of $250 \mathrm{~mm}$. In total, 43 specimens were tested in compression. The moisture content was determined and was above the fibre saturation point in all cases.

\subsection{Shear tests}

Shear tests (Sample S1) are particularly difficult to perform, since whatever type of specimen is chosen, the introduction of secondary stresses is inevitable. Standard test specimens as specified for instance in ASTM D143 (1995) determine the strength of small clear specimens (Rammer and McLean 1996). The results are difficult to interpret for structural applications. European standard EN 1193 specifies a method with bonded steel plates on the surface. This method is applicable to species easily adhering to steel, but for a species like azobé it is not possible. Therefore, shear tests have been performed on Ishaped beams in a five-point bending test. Although in this case bending stresses parallel to the grain develop as well as compression stresses perpendicular to the grain, this method does give reliable results that can be used in structural applications (Leicester and Breitinger 1992), Schickhofer (2001). Twenty-five beams were shaped into an I beam as shown in Fig. 1.

The test set-up is shown in Fig. 2. The span/depth ratio is $948 / 110=8.6$ compared to 20 or more for all the bending samples. The sizes of the supports and the loading points were $120 \mathrm{~mm}$ in length. However, the data analysis has been performed on the assumptions of point loads and point supports, in order to be able to use the values for practical design situations.

\subsection{Statistical data analysis}

\subsubsection{Normal, lognormal and Weibull distributions}

The test data have been analysed statistically. Average values, standard deviations and minimum and maximum values were determined for each sample and for the population sample $\mathrm{P} 1$, respectively. Sample P1 was analysed to verify whether the properties 


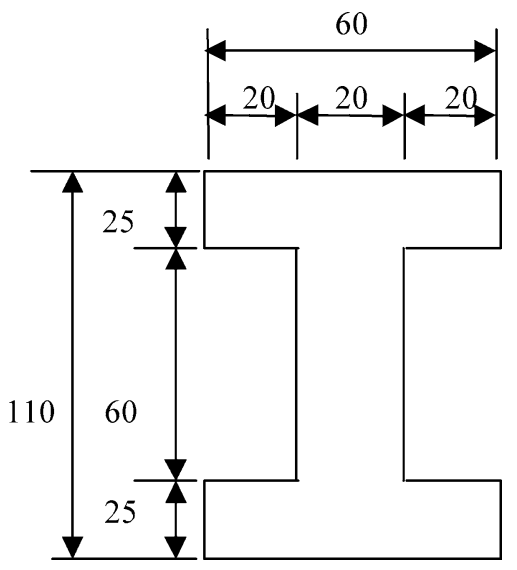

Fig. 1 Cross section of shear specimens (in $\mathrm{mm}$ )

Abb. 1 Querschnitt der Scherversuchskörper (in mm)

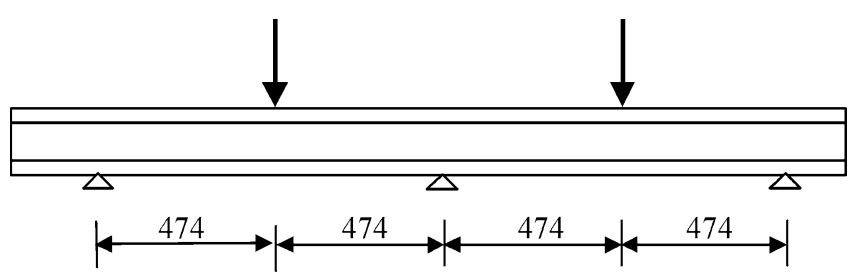

Fig. 2 Five-point bending test with two spans of $948 \mathrm{~mm}$ Abb. 2 Fünf-Punkt-Biegeprüfung mit zwei Spannweiten von je 948 $\mathrm{mm}$

can best be described by a normal, lognormal or a Weibull distribution. Benjamin and Cornell (1971) suggest using nine intervals for the sample size concerned, but this would lead to more complex boundaries for each interval. In this case, a histogram of the data with
12 intervals of $10 \mathrm{~N} / \mathrm{mm}^{2}$ was determined starting at $40 \mathrm{~N} / \mathrm{mm}^{2}$. The properties (average $\mu$ and standard deviation $\sigma$ ) for the lognormal distribution are determined as

$\mu=\frac{\sum \ln \left(x_{i}\right)}{n} \quad$ and $\sigma=\sqrt{\frac{n \sum \ln \left(x_{i}\right)^{2}-\left(\sum \ln \left(x_{i}\right)\right)^{2}}{n(n-1)}}$

The three-parameter Weibull distribution is written as

$P(f)=1-\mathrm{e}^{\left(-\left(x_{i}-x_{0}\right) / m\right)^{k}}$

where $P(f)$ is the probability of failure, $m$ the scale parameter, $k$ the shape parameter and $x_{0}$ the location parameter.

The location parameter $x_{0}$ may be chosen to be zero. In that case, the three-parameter Weibull distribution reduces to a two-parameter distribution. Both two- and three-parameter Weibull distributions have been applied to describe the test results. The values of the threeparameter Weibull distribution, have been determined using the freely available software Dataplot (NIST 2001). For the three-parameter Weibull distribution Dataplot takes the lowest value of the test data as the location parameter.

\subsubsection{Least-square method for three-parameter Weibull distribution}

A simple least-square method (1sm) was developed to determine the influence of the location parameter $x_{0}$ on the value of the scale and shape parameters $m$ and $k$,

Table 1 Overview of test samples and test results

Tabelle 1 Übersicht über die Stichproben und Versuchsergebnisse

\begin{tabular}{|c|c|c|c|c|c|c|c|c|c|c|c|c|}
\hline Sample & No. & $\begin{array}{l}\text { Width } \\
(\mathrm{mm})\end{array}$ & $\begin{array}{l}\text { Depth } \\
(\mathrm{mm})\end{array}$ & $\begin{array}{l}\text { Span } \\
(\mathrm{mm})\end{array}$ & $\begin{array}{l}\text { Ratio } \\
\text { S/D }\end{array}$ & $\begin{array}{l}\text { Moisture } \\
(\%)\end{array}$ & \multicolumn{4}{|c|}{ Density $\left(\mathrm{kg} / \mathrm{m}^{3}\right)$} & \multicolumn{2}{|c|}{ Static MoE } \\
\hline N2 & 40 & $150-276$ & 30 & 750 & 25 & $>30$ & - & - & - & - & 16,450 & 2,330 \\
\hline N3 & 40 & $179-315$ & 60 & 1,500 & 25 & $25-43$ & 880 & Oven-dry & 23 & 2.6 & 18,490 & 2,470 \\
\hline N4 & 39 & 300 & 60 & 5,400 & 90 & $17-50$ & 1,120 & $12 \%$ & 12 & 11 & 15,660 & 1,720 \\
\hline N5 & 16 & 75 & 150 & 3,000 & 20 & $>30$ & 1,110 & $12 \%$ & 25 & 2.5 & 17,620 & 2,330 \\
\hline $\mathrm{O} 2$ & 20 & $135-260$ & $50-60$ & 1,500 & $30-25$ & $>30$ & - & - & - & - & 18,490 & 2,420 \\
\hline $\mathrm{O} 3$ & 22 & $153-283$ & 50 & 1,500 & 30 & $>30$ & - & - & - & - & 17,380 & 2,370 \\
\hline \multirow[t]{3}{*}{$\mathrm{P} 1$} & 258 & - & - & - & - & - & 1,120 & $12 \%$ & 59.5 & 5.3 & 17,200 & 2,510 \\
\hline & & & & & & & \multicolumn{4}{|c|}{ (based on N4, N5, N6) } & & \\
\hline & & $\begin{array}{l}\text { Thickness } \\
(\mathrm{mm})\end{array}$ & $\begin{array}{l}\text { Width } \\
(\mathrm{mm})\end{array}$ & $\begin{array}{l}\text { Length } \\
(\mathrm{mm})\end{array}$ & & & & & & & & \\
\hline S1 & 25 & & See Fig. 1 & & 8.6 & $>30$ & & $12 \%$ & - & - & 13,670 & 1,330 \\
\hline
\end{tabular}

\footnotetext{
${ }^{a}$ Corrected values for mean and standard deviation: Eqs. 6 and 7
} 
respectively. The procedure to determine $x_{0}, k$ and $m$ is as follows. First, the cumulative probability function was determined based on the histogram of Fig. 3. Secondly, the value of $x_{0}$ was varied from 0 to $50 \mathrm{~N} / \mathrm{mm}^{2}$, the latter being close to the minimum strength value found in the tests. For each value of $x_{0}$, the least sum of squares between the test data and the Weibull distribution parameters $k$ and $m$ was determined where $k$ and $\mathrm{m}$ were optimised using the Solver routine in Excel. Then, the minimum value of the least sum of squares was taken as the optimal value for $x_{0}, k$ and $m$. In this way, it is ascertained that data in the lower and upper tail of the distribution are weighted equally as data in the centre, even though in the centre much more test data are available. This is an alternative for tail fitting, which requires large datasets (Ranta-Maunus 2001).

\subsubsection{Determination method of characteristic values of samples}

European standard EN 384 specifies a method for the derivation of characteristic values for samples with at least 40 test results (Fewell and Glos 1988). Because not all samples fulfil this requirement, characteristic values of the individual samples as well as for the population sample have been determined using the Bayesian method given in ISO 2394 (1998). According to this method, the fifth-percentile characteristic value of a sample $R_{k}$ can be determined as:

$R_{k}=m_{R}-t_{v d} s_{R} \sqrt{\left(1+\frac{1}{n}\right)}$

where $m_{R}$ is the mean value of the sample, $s_{R}$ the sample standard deviation of the sample, $t_{v d}$ the coefficient of

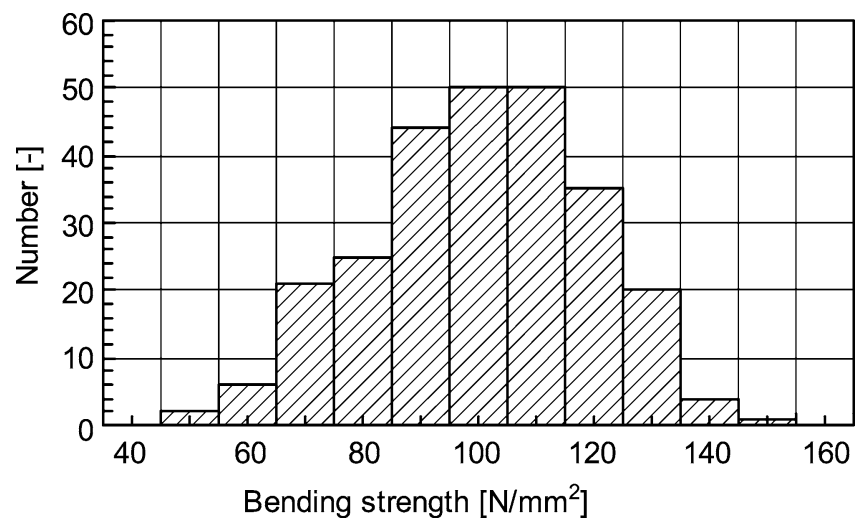

Fig. 3 Distribution of bending test results (Sample P1) Abb. 3 Verteilung der Biegefestigkeit von Bongossi

the Student distribution (Confidence level $=0.75$ ) and $n$ is the number of tests.

The value of $t_{v d}$ depends on the degrees of freedom $v$ $(=n-1)$. This means that the fewer test results available, the larger the value of $t_{v d}$ results. For materials where the standard deviation of the population is known a priori, the degree of freedom may be based on $n=\infty$. In this case, there are nine samples available from many different sources, and it may be assumed that the standard deviation of the whole population is known from Sample P1. As a result, $t_{v d}$ is taken as 1.64 to determine a samples' fifth-percentile strength value. The characteristic value of Sample P1 has also been determined as the fifth-percentile value of the fitted distributions.

For the shear tests, the procedure for the determination of the characteristic value is more complicated. In each five-point bending test, two shear tests are performed, one in each span. Consequently, every time a

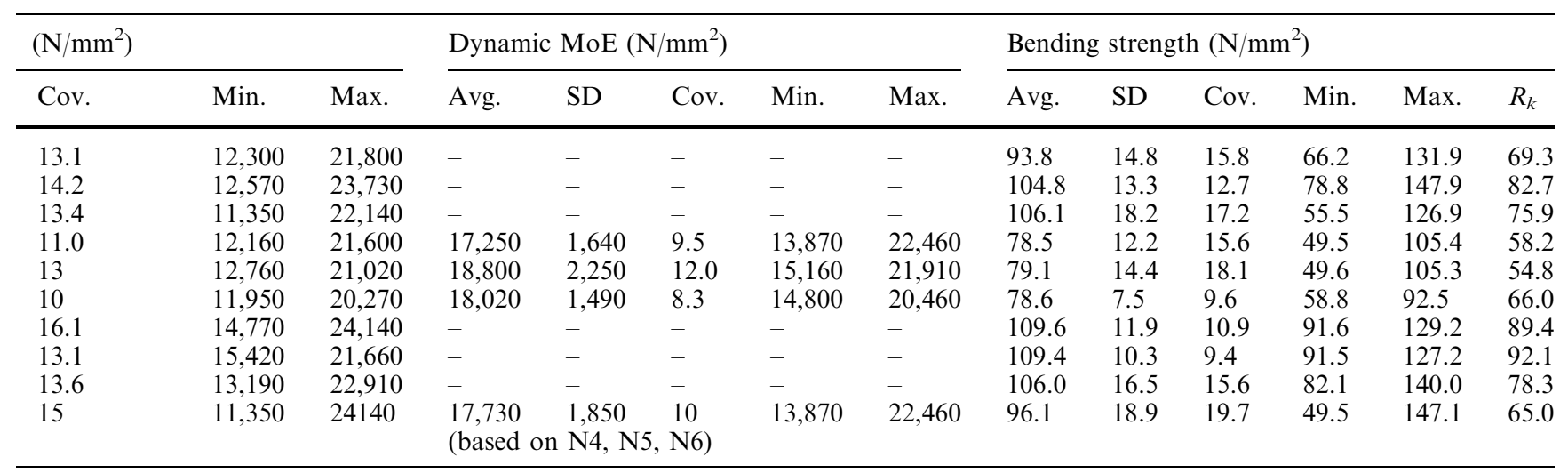

Compression strength $\left(\mathrm{N} / \mathrm{mm}^{2}\right)$

\begin{tabular}{llllllllllllllll}
\hline- & - & - & - & - & - & - & - & & 69.7 & 6.5 & 9.3 & 56.4 & 84.3 & 58.9 \\
& & & & & & & & & \multicolumn{2}{c}{ Shear strength $\left(\mathrm{N} / \mathrm{mm}^{2}\right)$} & \\
\hline 9.8 & 10,860 & 15,630 & - & - & - & - & - & - & & $17.7^{\mathrm{a}}$ & $2.1^{\mathrm{a}}$ & 12.0 & 13.4 & 20.2 & 14.2 \\
\hline
\end{tabular}


beam fails, the lowest value of the 'two' tests is found and the result has to be adjusted statistically. Van Douwen et al. (1958) have shown that for this case the following relationships apply:

$x_{1}=x_{2}+c_{1} \sigma_{2}$

$\sigma_{1}=c_{2} \sigma_{2}$

where $x_{1}$ and $x_{2}$ are the average value of the whole and the tested population, $c_{1}$ and $c_{2}$ correction factors for the mean and standard deviation $\sigma_{1}$ and $\sigma_{2}$ are the standard deviations of the whole and the tested population.

For symmetrically loaded specimens as in the fivepoint bending tests, and assuming that the results can be described by a normal distribution, the correction factors are $c_{1}=0.68$ and $c_{2}=1.21$. With these results, the characteristic shear strength has been determined using Eq. 4. The modulus of elasticity of each beam has been determined in four-point bending by applying a load while the middle support was removed. The density of each beam was also determined.

\section{Results and discussion}

Table 1 gives the average values, standard deviation and coefficient of variation and minimum and maximum value of all samples tested including the population P1 sample. The latter is done to obtain information on the whole population and to be better able to derive (characteristic) values for the species and relationships between properties, such as the modulus of elasticity and strength. In addition, it becomes possible to determine, which statistical distribution function fits the data best.

\subsection{Bending strength}

The distribution of the bending strength (sample P1) is shown in Fig. 3. The average strength of the sample of 258 specimens is determined as $96.1 \mathrm{~N} / \mathrm{mm}^{2}$ and the standard deviation as $18.9 \mathrm{~N} / \mathrm{mm}^{2}(\operatorname{cov} .=0.20)$. Figure $4 \mathrm{a}-\mathrm{c}$ give probability plots of the test results, based on the assumption of a normal, lognormal or Weibull distribution, respectively. From the three distributions, the normal distribution seems to best describe the test data over the full range, while the lognormal deviates on both lower and upper tail and the Weibull deviates around the lower tail only. The cumulative density functions of the normal and the three-parameter Weibull distributions are shown in Fig. 5. The parameters of all the distributions are summarized in Table 2.

The non-parametric value of the characteristic strength is $66.0 \mathrm{~N} / \mathrm{mm}^{2}$. The lower fifth-percentile value is $65 \mathrm{~N} / \mathrm{mm}^{2}$ according to the method given in ISO 2394. Therefore, the differences between the distributions are relatively small and no preference for either one distribution can be given. The three-parameter Weibull
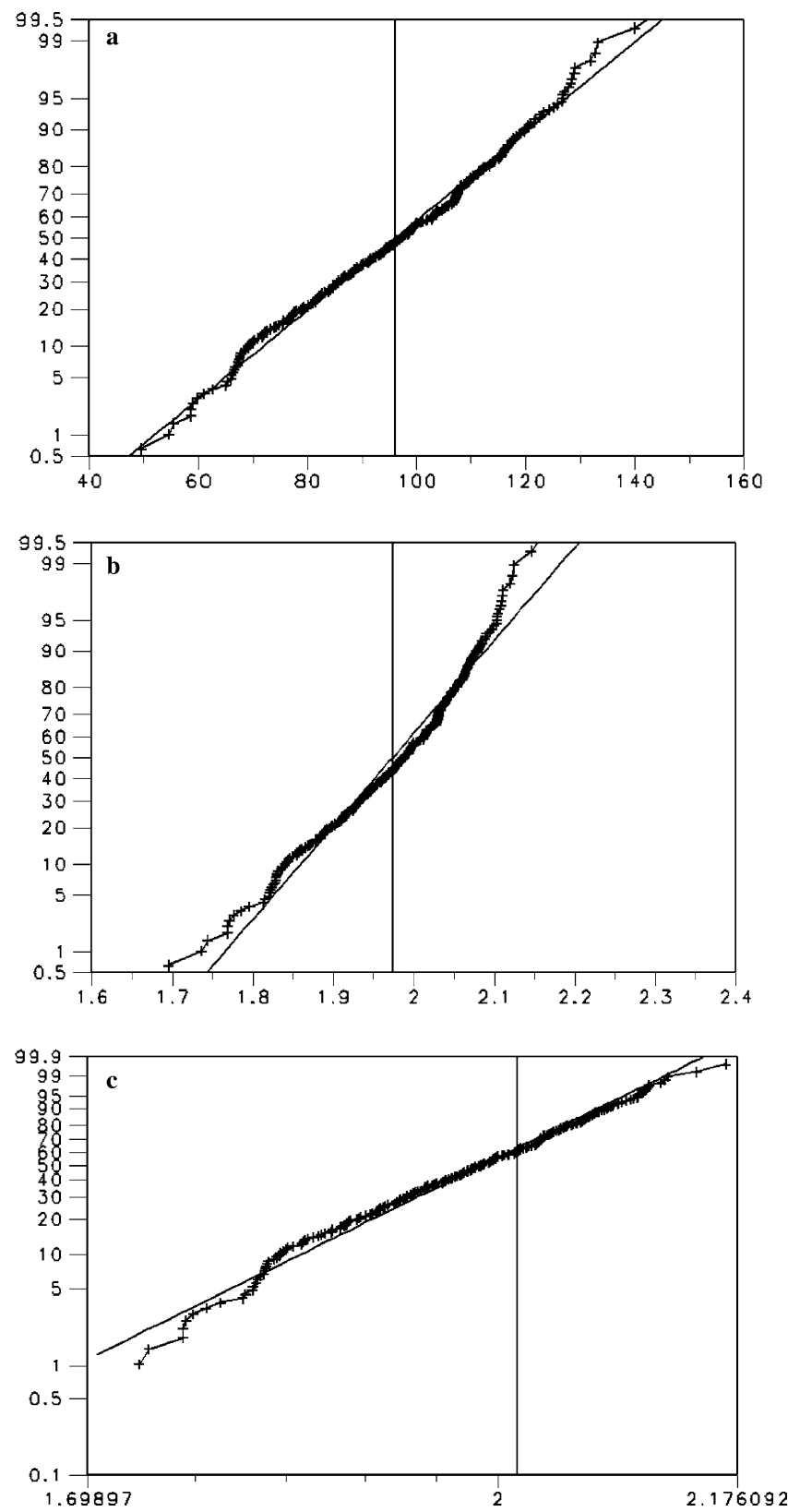

Fig. 4 Probability plots for the bending strength; a Normal probability $\left(\mathrm{N} / \mathrm{mm}^{2}\right)$; b Lognormal probability $\left[\log \left(\mathrm{N} / \mathrm{mm}^{2}\right)\right]$; c Weibull probability $\left[\log \left(\mathrm{N} / \mathrm{mm}^{2}\right)\right]$. Thin lines represent the distributions for which the parameters are given in Table 2

Abb. 4 Summenhäufigkeit der Biegefestigkeit; a Normalverteilung $\left(\log \left(\mathrm{N} / \mathrm{mm}^{2}\right)\right)$; b Lognomalverteilung $\left(\log \left(\mathrm{N} / \mathrm{mm}^{2}\right)\right)$; c Weibullverteilung $\left(\log \left(\mathrm{N} / \mathrm{mm}^{2}\right)\right)$. Die Verteilungsparameter sind in Tabelle 2 angegeben

distribution determined with Dataplot takes the lowest value of the test data $\left(49.5 \mathrm{~N} / \mathrm{mm}^{2}\right)$ as the value for the location parameter. However, the three-parameter Weibull distribution determined on the basis of the histogram gives a location parameter that is far lower, namely $18.33 \mathrm{~N} / \mathrm{mm}^{2}$. The result is that in the first case a slight overestimation of the fifth-percentile value is obtained, while in the second case it is the opposite, but the differences remain small. 


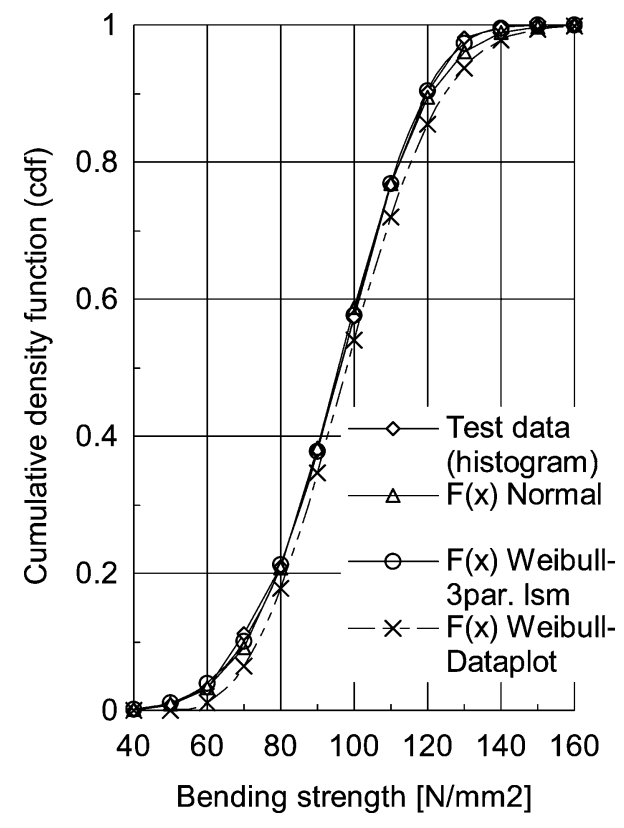

Fig. $5 \mathrm{Cdf}$ for the bending strength of azobe and three statistical distributions. Data of Lognormal and two-parameter Weibull are given in Table 2

Abb. 5 Summenhäufigkeitsverteilung von Bongossi und drei Häufigkeitsverteilungen. Ergebnisse für Lognormal und 2-parameter Weibull Verteilung sind in Tabelle 2 angegeben

\subsection{Depth effect}

The depth effect has been analysed by dividing all strength data by the average value of the bending strength with a depth of $150 \mathrm{~mm}$. The average value of the strength was $90.0 \mathrm{~N} / \mathrm{mm}^{2}$. Bending strength values as a function of the depth, the depth effect equation of Eurocode 5 (2002) and the regression equation for azobé are shown in Fig. 6. The exponent of the depth effect is determined to be 0.103 and Eq. 1 adapted to azobé reads accordingly

Table 2 Distribution parameters and characteristic values for the bending strength

Tabelle 2 Verteilungsparameter und charakteristische Werte der Biegefestigkeit

\begin{tabular}{|c|c|c|c|c|}
\hline \multirow[t]{2}{*}{ Distribution } & \multicolumn{4}{|c|}{ Parameter } \\
\hline & Mean & SD & $f_{0.05}$ & \\
\hline Normal (Fig. 4) & 96.09 & 18.91 & 64.99 & \\
\hline Lognormal (Fig. 4) & 1.97 & 0.21 & 66.95 & \\
\hline \multirow[t]{2}{*}{ Distribution } & \multicolumn{4}{|c|}{ Parameter } \\
\hline & Scale & Shape & Location & $f_{0.05}$ \\
\hline Weibull 2-par. (Fig. 4) & 103.78 & 5.77 & - & 62.02 \\
\hline Weibull 3-par. & 55.38 & 2.73 & 49.52 & 68.18 \\
\hline Weibull lsm-cdf 2-par & 103.57 & 5.64 & - & 61.17 \\
\hline Weibull lsm-cdf 3-par & 85.06 & 4.54 & 18.33 & 62.58 \\
\hline
\end{tabular}

$k_{h}=\left(\frac{150}{h}\right)^{0.103}$

For practical applications a value of 0.1 can be used. The characteristic values of the individual samples are also shown in Fig. 6 and although a slight increase in characteristic values for smaller depths can be observed, it is small and could be neglected. The depth effect differs from softwoods due to failure by grain deviation and the absence of knots. However, the procedure for the assignment of species and grades to a strength class requires the application of the depth effect according to Eq. 1, and this has a negative influence on the design strength values for ultimate limit states of beams with a depth of $150 \mathrm{~mm}$ and more.

\subsection{Modulus of elasticity}

For the static modulus of elasticity, the average value and standard deviation are 17,200 and $2,500 \mathrm{~N} / \mathrm{mm}^{2}$, respectively (cov. $=0.15)$. In Fig. 7 , the probability plots of the static modulus of elasticity are shown. Clearly, the modulus of elasticity is best described using a lognormal distribution. The parameters of the three distributions are given in Table 3. The coefficient of determination $\left(R^{2}\right)$ between the static and dynamic modulus of elasticity is 0.8 and the ratio between the average value of the dynamic MoE and the static MoE was 1.09. The prediction of the bending strength using the modulus of elasticity is not very precise. The coefficient of determination between static MoE and MoR $(n=254)$ is 0.41 and between dynamic MoE and $\operatorname{MoR}(n=74)$ it is 0.05 . Figure 8 gives the relationship between static MoE and MoR. Four test results showed a modulus of elasticity of more than $20,000 \mathrm{~N} / \mathrm{mm}^{2}$, combined with a relatively

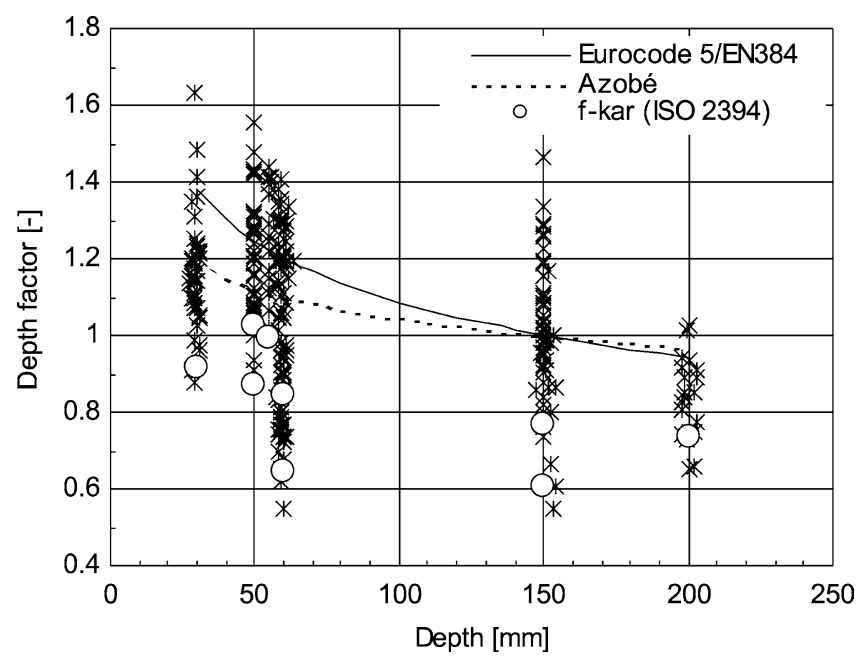

Fig. 6 Depth effect in azobé based on a reference depth of $150 \mathrm{~mm}$. The relative characteristic values of the individual samples are indicated with $\mathrm{O}$

Abb. 6 Höheneffekt für Bongossi auf der Basis einer Referenzhöhe von $150 \mathrm{~mm}$. Die charakteristischen Werte der Teilstichproben sind mit $\mathrm{O}$ gekennzeichnet 

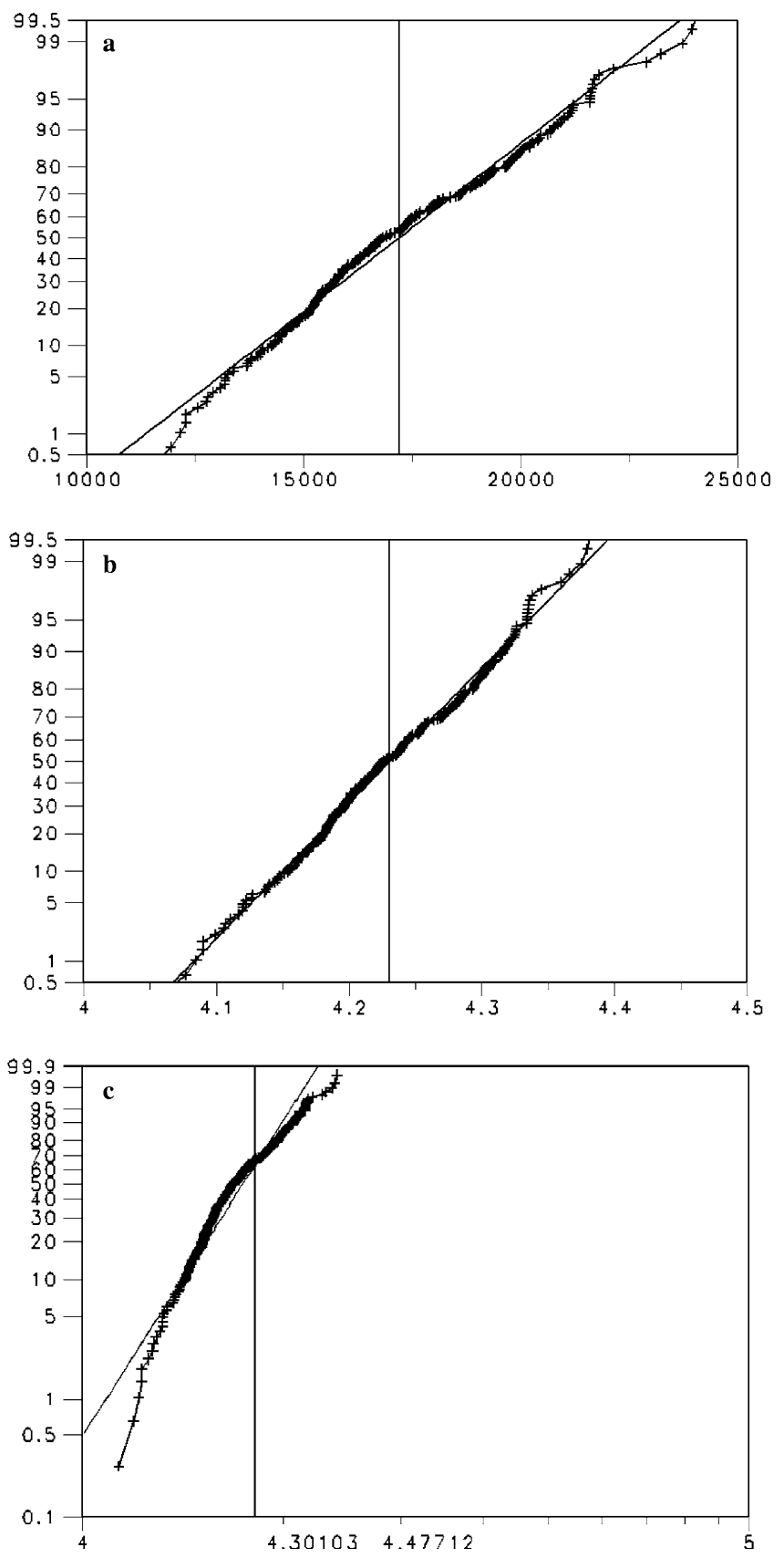

Fig. 7 Probability plots for the static modulus of elasticity; a Normal probability $\left(\mathrm{N} / \mathrm{mm}^{2}\right)$; b Lognormal probability $[\log (\mathrm{N} /$ $\left.\left.\mathrm{mm}^{2}\right)\right]$; c Weibull probability $\left[\log \left(\mathrm{N} / \mathrm{mm}^{2}\right)\right]$. Thin lines represent the distributions for which the parameters are given in Table 3

Abb. 7 Summenhäufigkeit des statischen E-moduls; a Normalverteilung $\left(\mathrm{N} / \mathrm{mm}^{2}\right)$; b Lognormalverteilung $\left(\log \left(\mathrm{N} / \mathrm{mm}^{2}\right)\right)$; $\mathbf{c}$ Weibullverteilung $\left(\log \left(\mathrm{N} / \mathrm{mm}^{2}\right)\right)$. Die Verteilungsparameter sind in Tabelle 3 angegeben

low strength. Although there is no obvious reason to omit these data points from the analysis, $R^{2}$ increases to 0.54 when this is done and the result becomes more in line with those obtained from softwood data (Blass and Gard 1994). These four data points are also responsible for the absence of a correlation between dynamic MoE and MoR. This indicates that stress wave analysis is not
Table 3 Distribution parameters for the static modulus of elasticity Tabelle 3 Verteilungsparameter für den statischen E-modul

\begin{tabular}{llll}
\hline \multirow{2}{*}{ Distribution } & \multicolumn{2}{l}{ Parameter } & \\
\cline { 2 - 4 } & Mean & SD & \\
\hline Normal (Fig. 7) & 17,200 & 2,500 & \\
Lognormal (Fig. 7) & 4.23 & 0.063 & \\
\hline Distribution & Parameter & & \\
\cline { 2 - 4 } & Scale & Shape & Location \\
\hline Weibull 2-par. (Fig. 7) & 18,290 & 7.21 & - \\
Weibull 3-par. & 6,600 & 2.48 & 11,350 \\
\hline
\end{tabular}

able to determine distinctly local defects that hardly affect the stiffness but have a large influence on the bending strength.

\subsection{Compression strength}

The compression tests of sample $\mathrm{Cl}$ resulted in an average compression strength of $69.7 \mathrm{~N} / \mathrm{mm}^{2}$ and a standard deviation of $6.5 \mathrm{~N} / \mathrm{mm}^{2}$, all in wet condition. The correlation between compression and bending strength is poor $\left(R^{2}=0.38\right)$, even though the specimens came from the same beam. The ratio between compression and bending for the samples $\mathrm{C} 1$ and sample N1 is 0.74 on the average value and 0.85 on the characteristic value, showing the influence of a lower coefficient of variation in the case of compression stresses. The characteristic value in wet condition is determined as $58.9 \mathrm{~N}$ $\mathrm{mm}^{2}$, compared to $32 \mathrm{~N} / \mathrm{mm}^{2}$ for the value of strength class D60 of EN 338, which is valid for dry conditions.

\subsection{Shear strength}

Out of 25 beams, 18 failed in a shear mode, while the other seven failed in a bending mode. Shear failure was either in the centre of the web or in the web near the flange. Using Eqs. 6 and 7, the average shear strength was determined at $17.7 \mathrm{~N} / \mathrm{mm}^{2}$ and the standard deviation was $2.1 \mathrm{~N} / \mathrm{mm}^{2}$. Uncorrected values were 16.5 and $1.8 \mathrm{~N} / \mathrm{mm}^{2}$, respectively. The coefficient of variation is $11.9 \%$, which is in the same range as for bending. No correlation between the modulus of elasticity and the shear strength could be established, but since only a small number of data is available, definite conclusions cannot be drawn. However, despite the small number of data, the wet characteristic value of $13.9 \mathrm{~N} / \mathrm{mm}^{2}$ is considerably higher than the characteristic value of $5.3 \mathrm{~N} / \mathrm{mm}^{2}$ as given in EN 338 for D60.

\subsection{Influence of moisture content on the strength}

Since, nearly all tests have been performed in wet condition, the characteristic values must be modified and related to dry conditions for engineering purposes. 


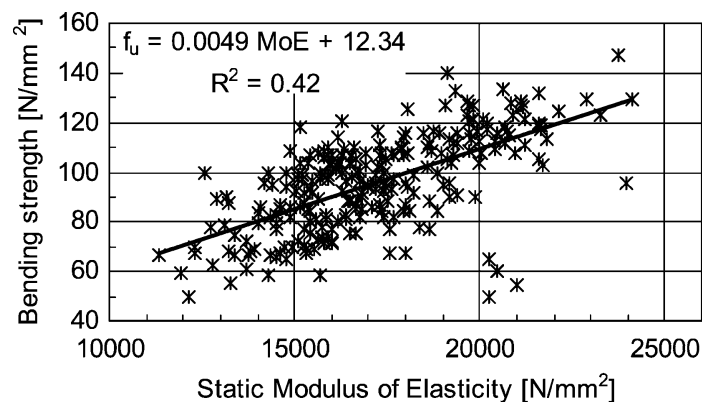

Fig. 8 Relationship between static modulus of elasticity and bending strength

Abb. 8 Abhängigkeit der Biegefestigkeit vom statischen E-modul

Only a few boards from sample N4 had moisture contents below fibre saturation point. The fibre saturation point for azobé varies between 25 for intermediate wood (the layer between sapwood and heartwood) and $30 \%$ for heartwood. The strength values of these boards were treated similarly as the values for the saturated boards, since in the range between 17 and $25 \%$ moisture content, the influence on the mechanical properties is considered to be small with respect the whole sample. From the test results, it can be concluded that for all strength properties the wet characteristic strength is higher than the dry characteristic strength from strength class D60. For bending strength, the Wood Handbook (1999) gives a ratio between the green state and $12 \%$ moisture content of 1.45 for both bending and shear and of 1.32 for compression. These values apply for defect free material. Most studies show an increase in bending strength with a decrease in moisture content below the fibre saturation point. However, for species or grades with large defects such an increase in strength is sometimes not found at the lower fifth-percentile level and the increase in strength depends on the location in the cumulative density function (Barrett and Lau 1989). Because the lower fifth-percentile is mainly determined by the presence of knots in these studies, it might be argued that for azobé this will not be similar. For engineering purposes, the following procedure could be adopted for structural tests on wet tropical hardwoods that are difficult to dry to a moisture content of about $12 \%$. The procedure is based on the fact that in design codes such as Eurocode 5 (2002) the average ratio of the $k_{\bmod }$ values between service class $1 / 2$ and 3 is 1.2 for all strengths. Applying this ratio leads to a dry characteristic bending strength of $78.0 \mathrm{~N} / \mathrm{mm}^{2}$, a compression strength of $70.7 \mathrm{~N} / \mathrm{mm}^{2}$ and shear strength of $16.7 \mathrm{~N} / \mathrm{mm}^{2}$. However, since no tests were performed with dry timber, it is not known whether the strength really increases as it does for softwood. Therefore, the dry characteristic strength values that were calculated may be used for structures in service class 3; it remains questionable, however, to assume these dry characteristic values for bending, compression and shear, respectively, for structures assigned to service classes 1 or 2 .

\section{Conclusions}

A large set of data for bending, compression and shear strength values of azobé has been analysed. The static bending strength can best be described using a normal distribution, while the static modulus of elasticity best fits a lognormal distribution. A three-parameter Weibull distribution may also be used but the determination of the location parameter $\sigma_{0}$ is complicated and depends on the software and procedure used. However, the influence of the choice of distribution on the lower fifth-percentile characteristic value of the bending strength is relatively small. This coincides with the observation made for spruce and pine by Ranta-Maunus (2001), and for reliability analysis a lognormal distribution might be used. To determine the characteristic value, the traditional statistical distribution can be used, and also the method given in ISO 2394, which is based on Bayesian statistics. The depth effect as it is observed in softwoods, is considerably less pronounced in a species like azobé in which the absence of knots results in a different failure behaviour. Values for compression and shear strength are considerably higher than the values given in strength class D60 in EN 338 to which azobé is assigned. To a lesser extent, this is also the case for the bending strength, Taking into account that all data were determined using wet specimens.

\section{References}

Barrett JD, Griffin H (1989) Size effects for Canadian dimension lumber, CIB-W18 Timber Structures, Paper 22-6-1, Berlin, German Democratic Republic, September

Barrett JD, Lau W (1989) Moisture content adjustments for ingrade data, CIB-W18 Timber Structures, Paper 22-6-2, Berlin, German Democratic Republic, September

Barrett JD, Fewell AR (1990) Size factors for the bending and tension strength of structural timber, CIB-W18 Timber Structures, Paper 23-10-3, Lisbon, Portugal, September

Benjamin JR, Cornell AC (1971) Probability statistics and decision for civil engineers. McGraw-Hill

Blass HJ, Gard WF (1994) Machine strength grading of timber, Pacific Timber Engineering Conference, vol 2. Gold Coast, Australia, pp 598-603

Bohannan W (1966) Effect of size on bending strength of wood beams. US Forest Products Laboratory, Bulletin No. 56

NIST (2001) Dataplot. National Institute of Standards and Technology, USA

Eurocode 5 (2002) Design of timber structures, Draft version

European Standard EN 338. Structural timber-strength classes

European Standard EN 384. Structural timber-determination of characteristic values of mechanical properties and density

European Standard EN 1193. Timber structures - structural timber and glued laminated timber-determination of shear strength and mechanical properties perpendicular to the grain

European Standard EN 1912. Structural timber-strength classes - assignment of visual grades and species

Frühwald E, Thelandersson S (2001) Nordic wood: reliability of timber structures, Reliability analysis, COST Action E24 Reliability Analysis of Timber Structures, Copenhagen Meeting, 19-20 October 2001

Fewell AR, Curry WJ (1983) Depth factor adjustments in the determination of characteristic bending stresses for visually graded timber. Structural Engineer, vol 61B, No.2 
Fewell AR, Glos P (1988) The determination of characteristic strength values for stress grades of structural timber. Part 1 . CIB-W18 Timber Structures, Paper 21-6-2, Parksville, Canada

Houtinstituut TNO (1961) Buig- en drukproeven bij azobé van handelskwaliteit en afmetingen en bijbehorend klein foutvrij hout (in Dutch). Report H-61-78

Houtinstituut TNO (1977) Sterkte eigenschappen van gebruikt en ongebruikt azobé (in Dutch). Report H-77-93

ISO 2394 (1998) General principles on reliability for structures

Leicester DE, Breitinger HO (1992) Measurement of shear strength. In: IUFRO S5.02 Proceedings, Nancy

NEN 5480, Quality requirements for timber-Species Azobé

Rammer DR, McLean DI (1996) Recent research on the shear strength of wood beams. In: Proceedings of the international wood engineering conference, vol 2, New Orleans, pp 96-103, 28-31 October 1996

Ranta-Maunus A (2001) Summary report on existing strength data. COST Action E24 Reliability Analysis of Timber Structures, Copenhagen Meeting, 19-20 October 2001
Schickhofer G (2001) Determination of shear strength values for GLT using visual and machine graded spruce laminations CIB W18 Timber Structures, Paper 34-12-6, Venice

Van der Linden MLR, Van de Kuilen JWG, Stolle P, Katsma H (1996) Full scale testing of timber sheet pile walls. World timber engineering conference, vol III, New Orleans, pp 557-564

Van Douwen AA, Kuipers J, Loof HW (1958) Corrections to the mean value and the standard deviation from test series with symmetrical test specimens, Stevin laboratory report. 4-82-9/oe5, Delft University of Technology

Weibull W (1939) A statistical theory of the strength of materials, Royal Swedish Institute for Engineering Research. In: Proceedings N. 141:45

Wood Handbook (1999) Forest Products Laboratory, Madison 